\title{
Clinical Evaluation and Surgical Management of Some Important Reproductive Problems of Intensively Raised Chickens in Zaria, Nigeria
}

\author{
Waziri I. Musa1, Sa'idu T. Muhammad² \\ ${ }^{1}$ Department of Veterinary Medicine, Ahmadu Bello University, Zaria, Nigeria \\ ${ }^{2}$ Veterinary Teaching Hospital, Ahmadu Bello University, Zaria, Nigeria \\ Email: ibwazkalt@yahoo.co.uk
}

Received 8 June 2015; accepted 6 July 2015; published 9 July 2015

Copyright (C) 2015 by authors and Scientific Research Publishing Inc.

This work is licensed under the Creative Commons Attribution International License (CC BY).

http://creativecommons.org/licenses/by/4.0/

(c) $\underset{\mathrm{EY}}{\mathrm{F}}$ Open Access

\begin{abstract}
Almost all healthy female chickens are expected to optimally produce eggs regularly. To maximize profits, nonproductive birds are often culled in commercial layer farms without due considerations to causes. Genetic and therapeutic manipulations to increase egg production per cycle often predispose birds to obstetric problems. Information on the detection and management techniques of reproductive abnormalities of the domestic chicken appear scarce. This study reports on clinical evaluation and surgical management of three major reproductive abnormalities of the commercial layer chickens. Egg yolk peritonitis, oviduct impaction and egg bound conditions were diagnosed and surgically managed following standard surgical procedures. Palpation and abdominocenthesis using flexible rubber catheter, abdomino-pelvic ultrasound scan and ventra-dorsal $\mathrm{X}$-ray techniques were used to establish diagnosis. In all reported conditions herein, surgery was employed to correct them. The study showed values of diagnostic imaging and surgery to correcting obstetric conditions of domestic chickens.
\end{abstract}

\section{Keywords}

Reproductive Problems, Surgery, Exotic Chicken

\section{Introduction}

Optimum egg production in flocks significantly depends on a healthy and functional reproductive system of the

How to cite this paper: Musa, W.I. and Muhammad, S.T. (2015) Clinical Evaluation and Surgical Management of Some Important Reproductive Problems of Intensively Raised Chickens in Zaria, Nigeria. Open Journal of Animal Sciences, 5, 325-331. http://dx.doi.org/10.4236/ojas.2015.53036 
chicken. Normal egg production measures the health status of a hen [1] and this ensures how profitable and sustainable a poultry production enterprise can be. Exotic commercial layer chickens have been genetically modified to lay more number of eggs per year; they are often administered egg boasters when productivity is not optimized, and sophisticated feeding regiments under intensive care are strictly adhered to thus making them potentially vulnerable to different reproductive tract disorders. Unfortunately, the aetiologies to these reproductive abnormalities appear to be poorly studied. Records of the morbidity rate of reproductive diseases of poultry ranged from moderate to as high as $35 \%$ while a moderate mortality rate of $15 \%$ is common but a significant decline in productivity of up to $40 \%$ has often been associated [2].

Egg peritonitis documented to be the most single common cause of mortality in commercial layers and breeders considered it as one of the serious reproductive problems to the commercial poultry industry. However, it appears to be kept out of the research scope mainly due to the fact that farmers are reluctant to report its sporadic occurrence. This consequently resulted in scanty information in field detection techniques and management of egg peritonitis [1] [3] [4].

Egg bound is a common condition in young layers in which there is difficulty in laying, or an egg cannot be normally laid and becomes lodged in the cloaca [5] [6]. The causes of egg bound are multi-factorial among which nutrition and conditions that lead to egg malformations play significant roles [7].

Oviduct impaction occurs sporadically when the oviduct is occluded by accumulation of eggs or masses of yolk and coagulated albumen [5]. Usually, the condition follows chronic salpingitis. The yolk-like materials in the oviduct may appear as concentric rings with the odour of a cooked egg [6] [7], such eggs may be enclosed by shell membranes and may be found in the abdominal cavity.

In Nigeria, few cases of reproductive abnormalities associated with losses in total egg production have been reported [8]-[10]. Abdu et al., [8] and Ate et al., [10] evaluated common gross reproductive abnormalities of the domestic fowl in Zaria, Nigeria. Ate et al., [10] further believed that genital disorders were not easily detected in flocks clinically. This further aggravated economic loss, as such bird continued to feed without expected egg production in return [11]. Sufficient information on reproductive disorders, their impacts and especially their management in poultry in Zaria, Nigeria is not enough to justify farmers' management decisions. As far as our knowledge this study might be the first to investigate the surgical intervention in major reproductive abnormalities of the domestic fowl in Zaria, Nigeria.

\section{Case Presentations}

On the $11^{\text {th }}$ March, 2014, two 43-week-old live birds from the same flock of 4000 were presented to the Veterinary Teaching Hospital of the Ahmadu Bello University, Zaria, Nigeria with distended abdominal areas. Upon clinical examination, weakness, ruffled feathers, discomfort and intermittent straining were noticed. On abdominal palpation, one bird had massive, soft and fluid filled swollen abdomen while the second bird had hard palpable mass in the oviduct. Low grade (0.2\%) mortality in the flock with similar conditions was reported to sporadically occur (Figure 1).

\subsection{Diagnostic Procedures}

Feathers around the swollen abdomens were removed and the exposed area swapped using mild antiseptic (chlorhexidine) solutions. A $5 \mathrm{ml}$ syringe with $19 \mathrm{G}$ needle was carefully inserted and about $2 \mathrm{ml}$ straw-colored yolk was aspirated and taken to microbiology laboratory for bacterial culture and isolation (Figure 2).

The birds were taken to the diagnostic imaging laboratory of the VTH for ultrasound scan and X-ray. The birds were properly restrained on the dorsum and ventro-dorsal X-ray of the chickens was taken. Abdominopelvic ultrasound scans were also conducted. In the bird with fluid-filled abdomen, the radiograph showed marked soft tissue inflammation (pectoral and abdominal muscles), and broken soft shell eggs were seen in fluid-filled abdominal cavity. The radiograph also showed the bird' skeleton to have normal radiographic texture and position. The ultrasound showed hyperechogenic region and some pockets of anechogenic areas within the abdominal cavity. Other visceral structures were not adequately visualized. It was thus concluded that soft tissue inflammation occurred. The radiograph and ultrasound results of the second bird with hard palpable mass showed large sized breach presented egg lodged in the pelvic cavity. A flexible rubber catheter was inserted to further drain and reduce the fluid responsible for the swollen abdomen (catheterization) (Figure 3 and Figure 4). 


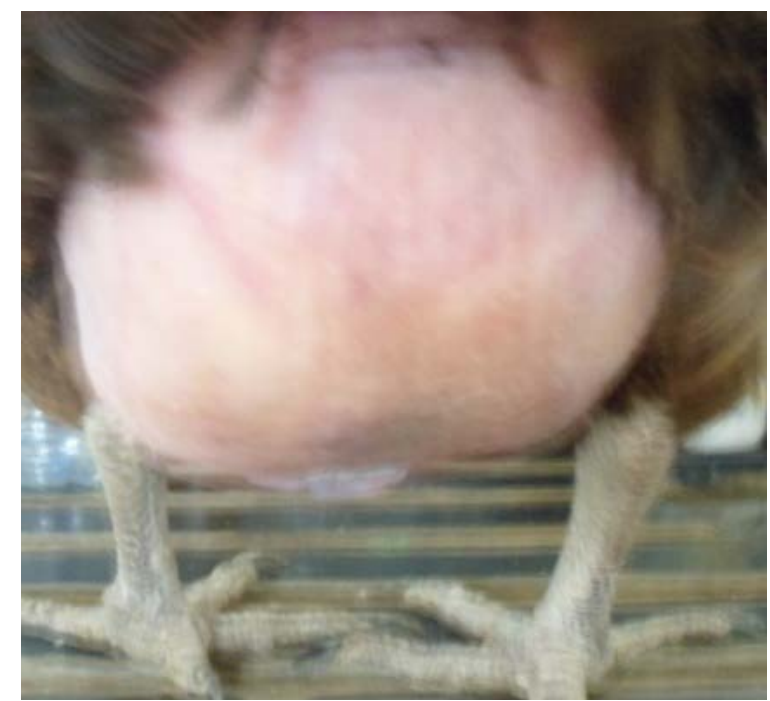

(a)

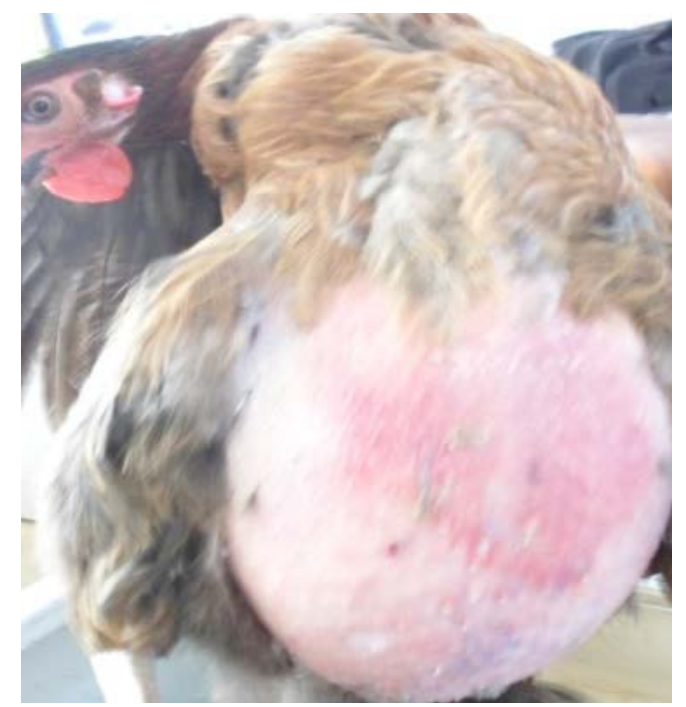

(b)

Figure 1. (a) Bird presented with hard distended abdomen and (b) a bird presented with soft fluid filled distended abdomen.

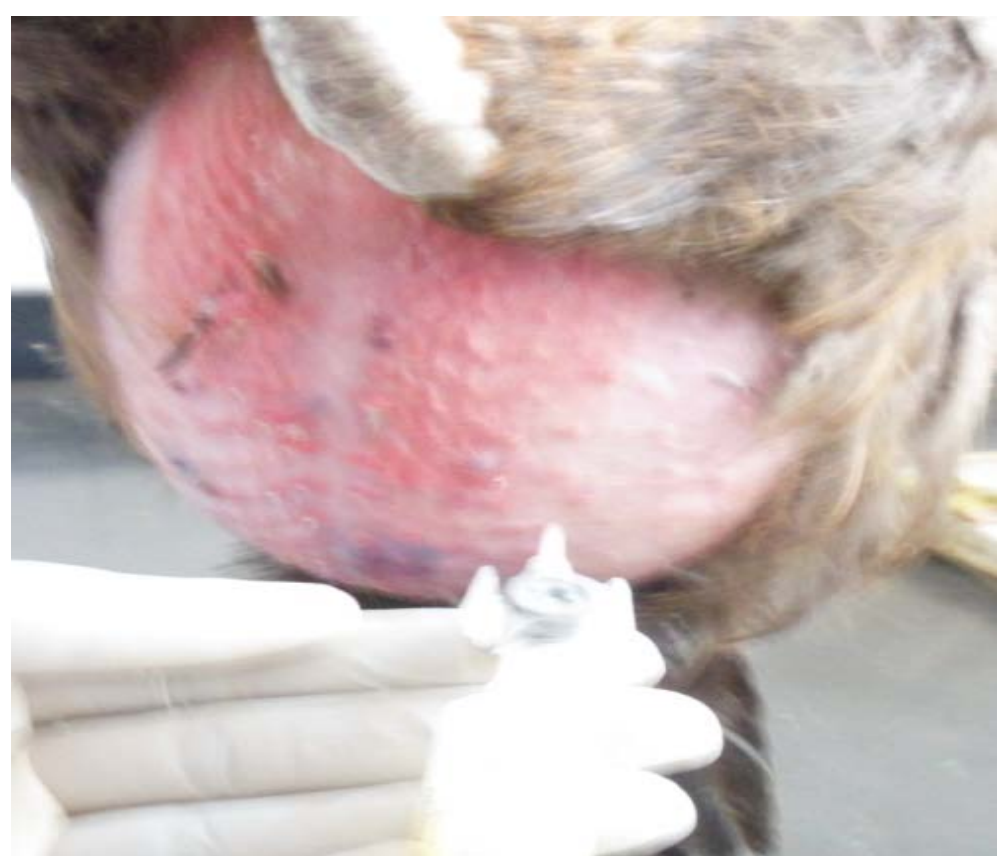

Figure 2. Aspiration of fluid filled distended abdomen using flexible catheter and syringe.

\subsection{Case Management}

Food and water were withheld for 12 and 6 hours before the surgery, respectively. About $8 \mathrm{~cm}$ of the ventral abdominal region (from the sternum to the cloaca) was plucked off feathers and scrubbed with soap and water. Pre-operative medication was achieved using Gentamycin ${ }^{\circledR}$ and piroxicam ${ }^{\circledR}$ (Pauco pharmaceutical industry, Nigeria Limited, Nigeria ) at $5 \mathrm{mg} / \mathrm{kg}$ IM and $0.5 \mathrm{mg} / \mathrm{kg}$ IM, respectively were administered 8 hours before the commencement of the operation. Anesthesia was achieved using ketamine hydrochloride (Ketamine ${ }^{\circledR}$-Rotex Medica Trittau, Germany) at $50 \mathrm{mg} / \mathrm{kg}$ IM, alongside atropine sulphate (AMOPIN ${ }^{\circledR}$-Yanzhou Xierkangtai Pharma. Co. Ltd, China) at $0.05 \mathrm{mg} / \mathrm{kg}$ IM and $2 \mathrm{ml}$ of $2 \%$ lidocaine hydrochloride (LIGNOVIT 20-AH ${ }^{\circledR}$ Vital Healthcare PVT, Ltd., Nashik, China) was infiltrated along the line of incision (Figure 5). 


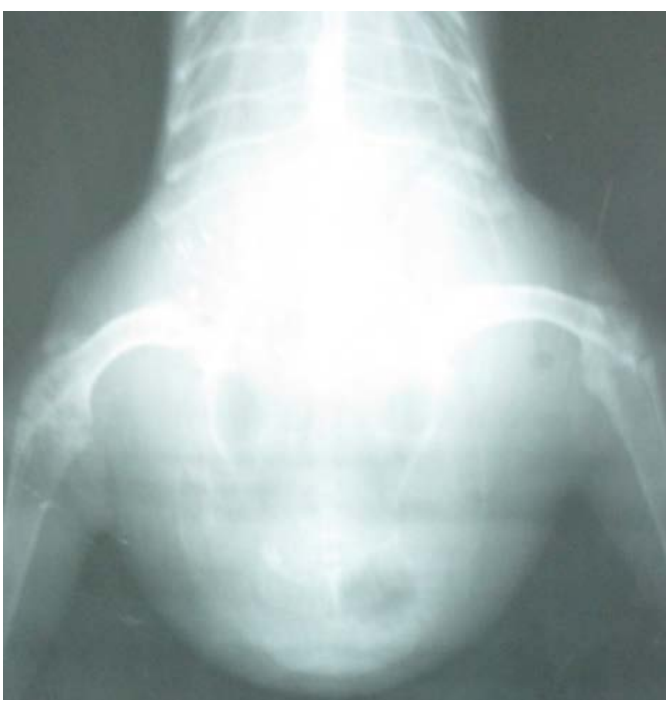

(a)

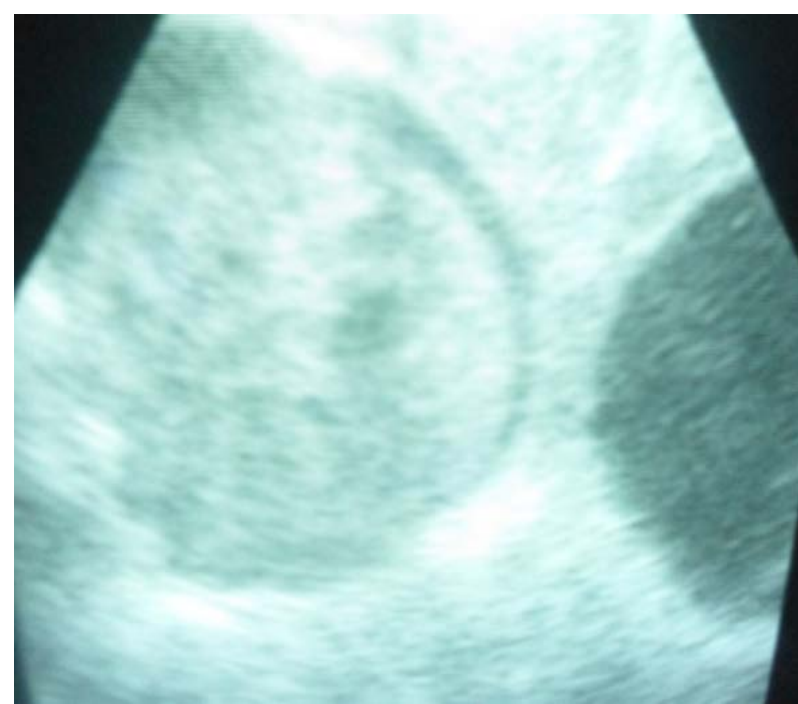

(b)

Figure 3. (a) Ventro-dorsal X-ray of a chicken showing marked inflammation of soft tissue and (b) abdomino-pelvic ultrasound scan indicating anechogenicfluid-filled region.

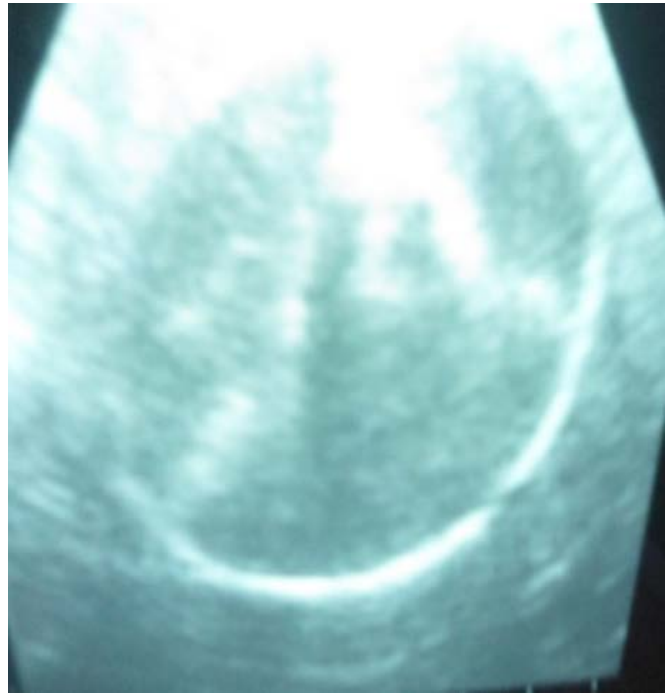

(a)

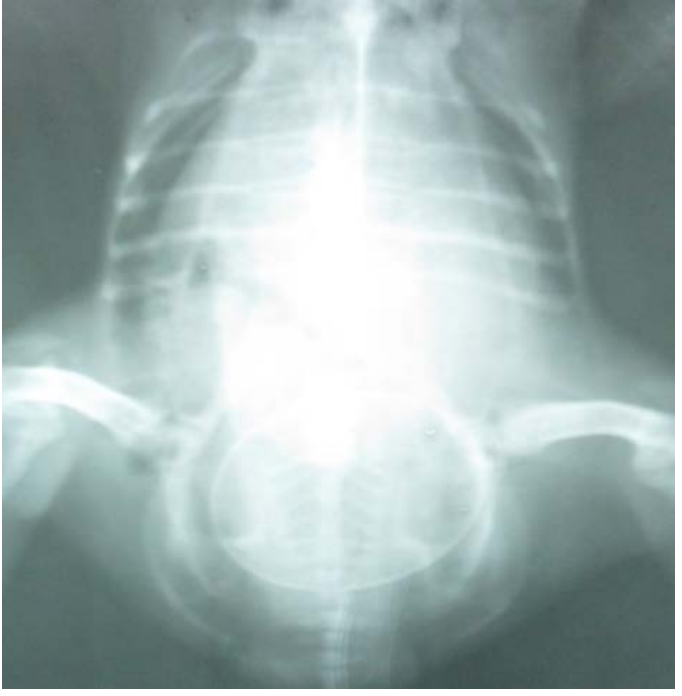

(b)

Figure 4. (a) Abdomino-pelvic ultrasound showing large sized egg and (b) ventro-dorsal X-ray showing large sized and breach presented egg in the pelvis of the chicken.

Each of the birds was placed in a dorsal recumbency on the surgical table, the ventral midline was aseptically prepared with $5 \%$ povidone iodine $\left(\right.$ WOSAN $^{(\mathrm{R})}$-Jawa International Ltd, Lagos, Nigeria) solution and the legs were abducted and retracted caudally. The abdominal cavity was accessed via ventral midline coelotomy. A 5 cm skin incision was made cranio-caudally (mid- post-ventral region from the sternum to the inter-pubic space). Stab incision was made on the linea alba to expose, isolate, exteriorize and position the uterus. Haemostasis was achieved using gauze and haemostatic forceps. The uterus was then incised $(3 \mathrm{~cm})$, broken eggs were carefully removed from the uterus. The bird was then caudally reclined at an angle of $20^{\circ}$ and the uterine lumen was flushed with $2 \%$ povidone iodine solution and uterine incision was sutured immediately by 2 rows of Cushing suture pattern with size 4/0 Ethicon-Vicryl ${ }^{\circledR}$ (Polyglactin 910-Johnson \& Johnson Jult, Belgium). The peritoneal cavity was lavaged with warm normal saline-povidone iodine solution, which was then suctioned with a suction machine. The linea alba, subcutis and the skin incisions were separately sutured using simple continuous suture 


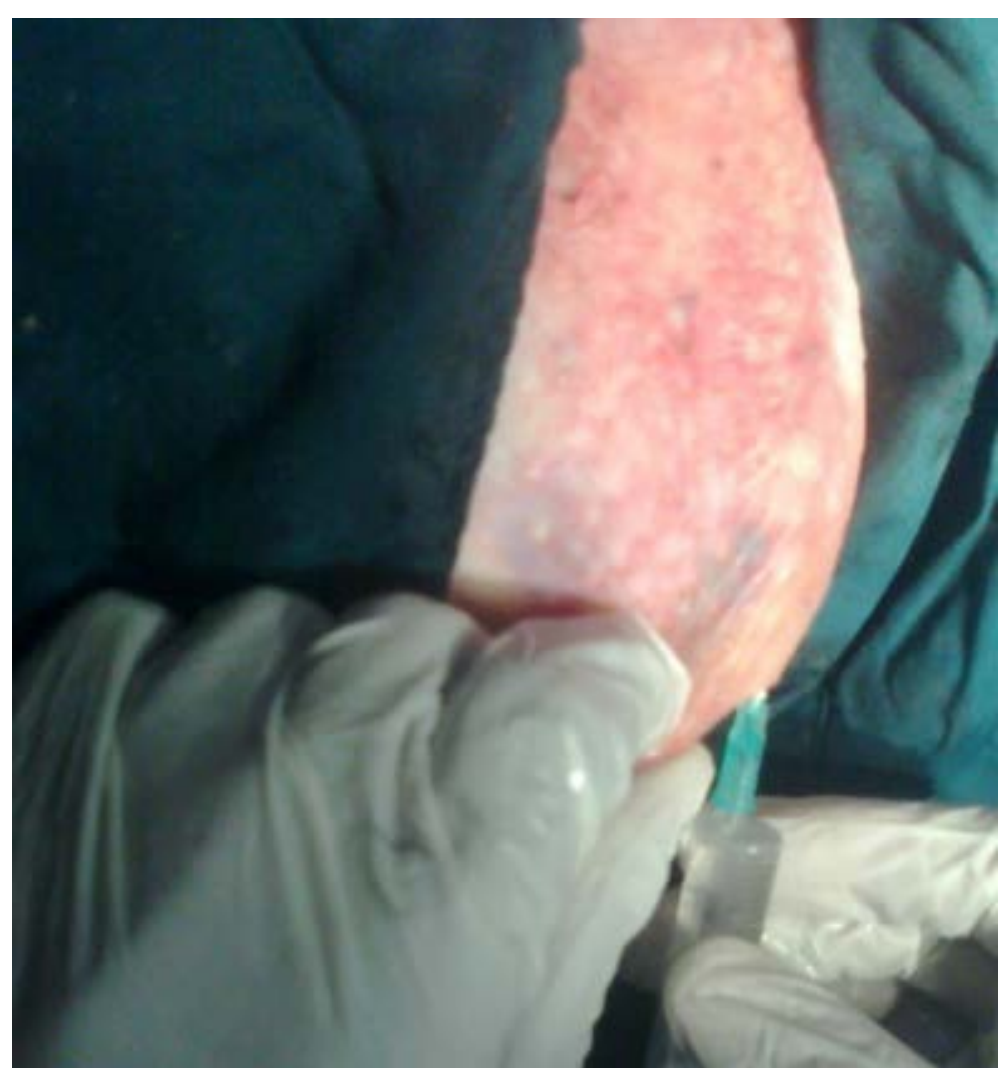

Figure 5. Infiltration of surgical site using local anesthesia (2\% lidocane).

pattern with 4/0 and 3/0 Ethicon-Vicryl ${ }^{(\mathrm{R})}$ (OGOTEX, NYLON MONOFILAMENT ${ }^{(\mathrm{R})}$-Shenzhen Runch Industrial Corp. China), respectively (Figure 6).

The birds were monitored until recovery from anesthesia, after which they were moved to a cage each for post-operative recovery and monitoring.

Postoperatively, the birds were maintained on gentamycin sulphate at $5 \mathrm{mg} / \mathrm{kg}$ o.d IM $\times 5 / 7$ and piroxicam at $0.5 \mathrm{mg} / \mathrm{kg}$ o.d IM $\times 3 / 7$. On the $7^{\text {th }}$ day post-surgery the birds was discharged.

\section{Discussion}

There have been documented reports of higher incidences (15.1\% - 27.5\%) of reproductive disorders in domestic fowl in some countries [12] [13], but few reports of reproductive abnormalities of birds have been documented in Zaria, Nigeria [8] [12]. Despite the fact that the birds were still feeding, the ovaries of the affected birds were regressed implying that they were not producing eggs. This seems to support the observation that reproductive disorders especially egg yolk peritonitis could be responsible for the major decline in egg production which is a major concern to the poultry farmers. Abdu et al. [8] observed most obstetric problems to have occurred in improved commercial layers where owners of such birds had put in huge financial investment thus made such owners promptly submitted dead and diseased birds to veterinary clinics for diagnosis and treatment. It is also the views of Abdu et al. [8] that local chickens in comparison to exotic chickens are not so productive, had less active reproductive organs producing fewer eggs per year, not stressed under the intensive management system, hence were less prone to reproductive disorders and had less chances of presentation for clinical attention.

Egg yolk is a very good medium for microorganisms' growth, hence a high possibility of bacterial infection associated with egg yolk found in the peritoneal cavity. Also viral diseases affecting the reproductive tract of birds could lead to frequent oophoritis and egg yolk peritonitis. Notably, amongst this are Newcastle disease and avian influenza. Escherichia coli isolated in this case falls within the findings of many authors to be responsible for egg peritonitis [1] [2] [4]. It was believed that E. coli could induce peritonitis without the predisposing fac- 


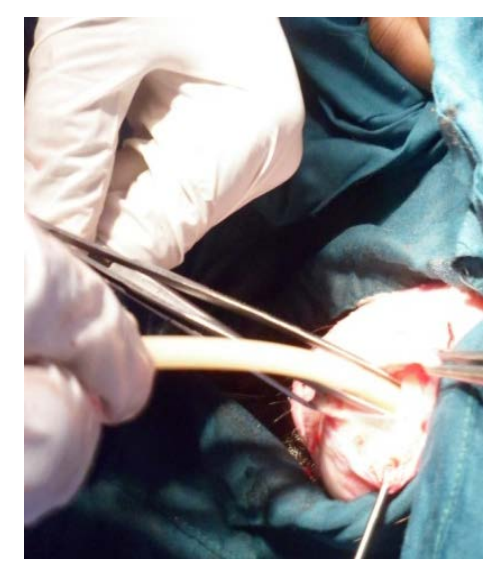

(a)

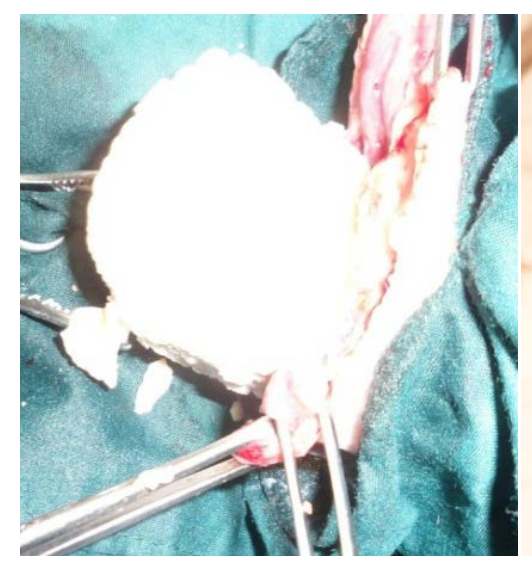

(b)

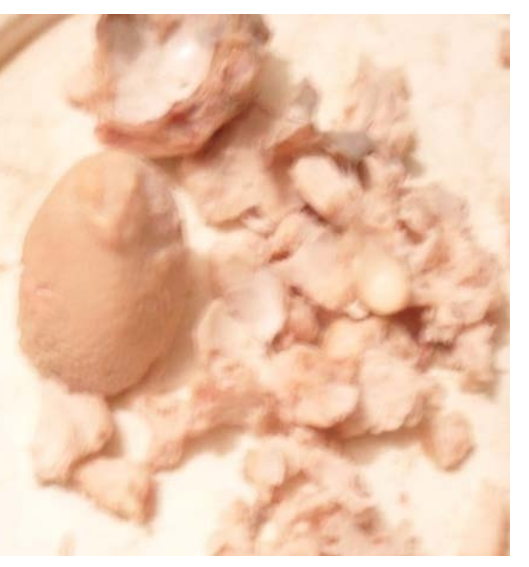

(c)

Figure 6. (a) Using a suction pump to evacuate egg yolk and debris from the oviduct and abdomen, (b) removal of bound egg and impacted materials within the uterus and abdomen and (c) bound egg and other impacted oviduct materials.

tors since it can ascend oviduct from cloaca to cause salpingitis and peritonitis [2] [4] [13]. In this study egg yolk, shelless and soft shell eggs were recovered from the uterus and the abdominal cavity. Severe adhesions of visceral organs, peritoneum and intestinal mesentery were also observed. The fact that egg yolk peritonitis could result from inability of released ova to enter the infundibulum, obstruction, rupture of oviduct or reverse peristalsis explains some of the above findings. Additionally, such ectopic ova may be resorbed without incidence of peritonitis, but several times, it is characterized by abdominal distention, depression, anorexia and lethargy as clinically observed in this case. Furthermore, the close proximity of ovary to many organs like the lungs, liver, kidneys, spleen, intestine and air sacs could make it highly likely to ascending infections from these organs thus accounting for some of the lesions seen in this study.

Oviduct and uterine egg obstructions were reported to be common only in young female birds at the initial stage of laying where surgery using ketamine hydrochloride was employed to correct it [14], however in this report the condition was observed in older birds.

In the efforts to making diagnosis of egg yolk peritonitis, history of egg laying, presenting clinical signs and complete blood count revealing leukocytosis with left shift neutrophilia (which is indicative of inflammatory responses) and their rates of occurrence have been very helpful in the diagnosis of egg yolk peritonitis but abdominocenthesis or laparatomy usually confirm this condition [15]-[18]. In this case abdominocenthesis revealed yolk intra-abdominally, leukocytosis with a left shift neutrophilia was evident from the haemogram, and laparatomy conducted during surgery and at postmortem, egg yolk, yolk clumps and severe organ adhesions were observed in the abdominal cavity. Chronic cases of egg yolk peritonitis were earlier reported with yolk forming clumps in the abdominal cavity and adherence of almost all visceral organs, air sacculitis and fibrinous deposits [9] [17] [19].

Ultrasound and radiograph are effective methods in detecting reproductive abnormalities [11] [19]. Their use in the avian species especially chickens appear limited majorly because the cost benefit of the procedure appears not to be effective. In this context surgical approach to correct such reproductive anomalies is always frowned at or neglected by owners or clinicians. However, a critical look at this scenario means salvaging affected chicken will terminate future expected eggs to be laid by the chicken. More critical is the experience obtained from its management that may confer confidence and enhance efficiency in handling similar conditions in highly priced birds. It is on these notes that these cases were managed.

Mild cases of egg yolk peritonitis may be managed medically while severe cases are corrected by surgical intervention through ventral midline celiotomy which provides an adequate access to both sides of coelomic cavity and provides an easy way to drain intra-abdominal fluids [11] [13] [19].

\section{Conclusion}

To fully appreciate avian practice in an attempt to help our feathered patients, we must initiate research projects targeting the epidemiology of avian obstetric problems, test hypothesis and gather relevant field experiences. 


\section{References}

[1] Jorda, F.T.W. (1998) Miscellaneous Conditions of Chickens, Turkeys and Ducks. 4th Edition, WB Saunders Co. Ltd., 392-421.

[2] Srinivasan, P., Balasubramaniam, G.A., Gopala, T.R., Murthy, K. and Balachandra, P. (2014) Prevalence and Pathology of Oviduct Impaction in Commercial White Leghorn Layer Chicken in Namakkal Region of India. Veterinary World, 2, 553-558. http://dx.doi.org/10.14202/vetworld.2014.553-558

[3] Kermer, I.F. (2008) Disorders of Avian Female Reproductive System. Avian Patholology, 9, 405-419. http://dx.doi.org/10.1080/03079458008418424

[4] Medina, H.A. (2008) Peritonitis in Commercial Egg Layers. Proceedings of the Midwest Poultry Federation Convention, St. Paul.

[5] Anne, L. and Girl, B. (2006) Egg Laying and Possible Problems. Tailfeathers Network, 2, 1-5.

[6] Bowles, H.L. (2002) Reproductive Diseases of Pet Bird Species. Veterinary Clinic of North America, Exotic Animal Practice, 5, 489-506. http://dx.doi.org/10.1016/S1094-9194(02)00008-7

[7] Rosen, L.B. (2012) Topics in Medicine and Surgery. Avian Reproductive Disorders. Journal of Exotic Pet Medicine, 21, 124-131. http://dx.doi.org/10.1053/j.jepm.2012.02.013

[8] Abdu, P.A., Sa’idu, L., Dandam, K.P. and Ruwaan, J.S. (2002) Some Reproductive Abnormalities in Domestic Fowls. Nigerian Journal of Animal Production, 29, 94-101.

[9] Onuoro, G.I. (1984) Seasonal Effect on the Egg Layer Pattern of Domestic Hens under the Deep Litter and Battery Systems of Management in Nsukka, Nigeria. Nigerian Veterinary Journal, 1, 18-22.

[10] Ate, I.U., Eze, E.C., Allam, L., Gberindyer, F., Wakawa, A.M. and Sa’idu, L. (2009) Gross Genital Disorders of the Avian Species Observed at Post Mortem at the Veterinary Teaching Hospital, Zaria, Nigeria over a Five Year Period. Nigerian Veterinary Journal, 30, 26-30.

[11] Roskopt, W.J. and Woerpel, R. (2000) Avian Obstetric Medicine. In: Bichard, J.S., Sherding, R.G., Eds., Saunders Manual of Small Animal Practice, 2nd Edition, W.B Sanders Company, Philadelphia, London, 1450-5100.

[12] De Matos, R. and Morrisey, J.K. (2005) Emergency and Critical Care of Small Psittacines and Passerines. Avian Exotic Pet Medicine, 14, 90-105. http://dx.doi.org/10.1053/j.saep.2005.04.004

[13] Hungerford, I.G. (1969) Diseases of Poultry including Cage Birds and Pigeons. 4th Edition, Angus and Robertson, 55-79.

[14] Joy, B. and Divya, T.R. (2014) Egg Bound and Vent Prolapsed in Chicken-A Review of Two Cases. Bangladesh Journal of Veterinary Medicine, 12, 91-92. http://dx.doi.org/10.3329/bjvm.v12i1.20472

[15] Singh, M.P., Methrota, R.L., Prassad, C.B. and Prassad, N.L. (1977) Studies on the Incidence of Egg Peritonitis, Salphingitis and Oophoritis in Laying Hens. Indian Veterinary Medicine Journal, 1, 38-42.

[16] Joyner, K.L. (1994) Theriogenology. In: Ritchie, B.L., Harrison, C.J., Harrison, I.R., Eds., Avian Medicine, Principles and Application. Lake Worth Wingers Publishing, 499-510.

[17] Kaikabo, A.A., Mustapha, A., Yaroro, I.I. and Gashua, M.M. (2007) Occurrence of Egg Impaction and Peritonitis in a Flock of Commercial Laying Hens in Damaturu, Nigeria. Nigerian Veterinary Journal, 28, 56-58.

[18] Speer, B. (1997) Diseases of the Urogenital System. In: Altman, R.B., Clubb, S.T., Dorrestein, G.M., Eds., Avian Medicine and Surgery, WB Saunders, Philadelphia, 625.

[19] Martin, H.D. (1990) Avian Reproductive Emergencies; Surgical Management. Veterinary Medical Record, 2, $250-253$. 